\title{
ANALISIS KEMAMPUAN KOGNITIF PESERTA DIDIK MELALUI PEMBELAJARAN PROBLEM BASE-LEARNING PADA MATERI PENJERNIHAN AIR
}

\author{
Rohaeni Nur Eli \\ Email : r.nureli@yahoo.com
}

\begin{abstract}
Abstrak
Penelitian ini bertujuan untuk memperoleh informasi mengenai penggunaan model pembelajaran $P B L$ terhadap peningkatan kemampuan kognitif peserta didik pada topik penjernihan air. Metode penelitian yang digunakan adalah kuasi eksperimen One Group Pretest-Postes Design, dengan subyek penelitian 31 orang peserta didik kelas XI di salah satu SMK Negeri di Kota Cimahi. Peserta didik dibagi ke dalam tiga kategori kelompok kemampuan, yaitu: tinggi, sedang dan rendah berdasarkan nilai rata-rata ulangan harian. Instrumen yang digunakan adalah tes tertulis pilihan ganda, essay, dan lembar observasi, angket pedoman wawancara. Peningkatan hasil belajar dihitung menggunakan rumus normalisasi gain dan uji hubungan rata-rata $N$-Gain . Hasil penelitian menunjukkan bahwa model pembelajaran ini menunjukkan peningkatan hasil belajar peserta didik secara signifikan dengan persentase $\mathrm{N}$ gain rata-rata sebesar $65.33 \%$ untuk seluruh peserta didik. Peningkatan hasil belajar tertinggi dicapai oleh peserta didik kategori tinggi $(N$-gain $=68 \%)$. Para peserta didik memberikan tanggapan yang positif terhadap pembelajaran, dan meeka merasa senang serta termotivasi dalam mengikuti pembelajaran menggunakan model yang diimplementasikan.
\end{abstract}

Kata Kunci : PBL, Kemampuan kognitif, dan penjernihan air

\begin{abstract}
This study aimed to obtain information on the use of PBL learning model to increase cognitive abilities of students on the topic of water purification. The method used is a quasi-experimental one group pretest-posttest design, with research subjects 31 students of class XI in one of SMK Kota Cimahi. Learners are divided into three categories ability groups, namely: high, medium and low based on the average value of daily tests. The instrument used is a multiple-choice written test, essay and observation sheets, questionnaires interview guidelines. Learning outcome is calculated using normalized gain and the average correlation test N-Gain. The results showed that this model shows an increase in the study of students significantly with the percentage of $\mathrm{N}$-gain average of $65.33 \%$ for all learners. Improved learning outcomes achieved by learners highest high category ( $\mathrm{N}$-gain $=68 \%$ ). The students responded positively to learning, and meeka feel happy and motivated in the following study uses a model that is implemented.
\end{abstract}

Keywords: PBL, cognitive ability, and water purification

\section{PENDAHULUAN}

Tujuan pendidikan nasional sebagaimana tertuang dalam Undang-Undang No. 20 Tahun 2003 bahwa pendidikan "bertujuan untuk berkembangnya potensi peserta didik agar menjadi manusia yang beriman dan bertakwa kepada Tuhan Yang Maha Esa, berakhlak mulia, sehat, berilmu, cakap, kreatif, mandiri, dan menjadi warga negara yang demokratis serta bertanggung jawab" (Kemendiknas, 2003: 3).
Jika kita berpijak dari dari undang-undang tersebut kita dapat temukan bahwa garis besar misi pendidikan nasional adalah untuk mencerdaskan kehidupan bangsa dan mengembangkan kualitas manusia seutuhnya. Pengembangan kualitas manusia ini menjadi keharusan, terutama dalam memasuki era perkembangan ilmu pengetahuan dan teknologi dewasa ini, agar generasi tidak menjadi korban dari globalisasi pengembangan itu sendiri. Upaya untuk 
mewujudkan hal tersebut telah lazim disebut dengan istilah pembelajaran.

Pembelajaran adalah proses interaksi peserta didik dengan pendidik dan sumber belajar pada suatu lingkungan belajar. Dengan kata lain, pembelajaran adalah proses untuk membantu peserta didik agar dapat belajar dengan baik Tujuan utama diselenggarakannya proses belajar adalah demi tercapainya tujuan pembelajaran. Tujuan tersebut utamanya adalah keberhasilan peserta didik belajar pada suatu mata pelajaran maupun pendidikan pada umumnya.

Berdasarkan hasil observasi di salah satu SMA Negeri di kota Cimahi dan Bandung menunjukkan bahwa hasil belajar siswa masih jauh yang diharapkan dikarenakan bahwa kegiatan pembelajaran masih didominasi oleh guru yang menyampaikan materi pembelajaran dengan metode ceramah. Sementara itu, peserta didik hanya memperhatikan dan cenderung pasif tanpa banyak terlibat dalam kegiatan pembelajaran serta lebih banyak berperan sebagai penerima informasi dari guru Wulandari (2011: 3).

Salah satu cara untuk meningkatkan kognitif peserta didik adalah dengan mencari model pembelajaran yang sesuai. Melalui $P B L$, peserta didik dapat dilatih menghadapi berbagai masalah baik itu masalah pribadi maupun masalah kelompok untuk dipecahkan sendiri-sendiri maupun secara bersama-sama. Hasil penelitian Muntaha dan Hartono (2013: 53) yang berjudul menunjukkan bahwa hasil belajar peserta didik dalam mengikuti pengembangan perangkat pembelajaran dilakukan dengan kategori baik serta $91,67 \%$ peserta didik dapat menuntaskan pembelajaran.

Hasil penelitian Arnyana (2006: 496) menjelaskan bahwa di antara model pembelajaran inovatif (kooperatif Group Investigation disingkat GI, PBL, dan Inkuiri) yang dibandingkan dengan pembelajaran tradisional yang memberikan hasil paling tinggi terhadap kreativitas peserta didik adalah pembelajaran dengan model $P B L$. Kedua hal tersebut menunjukkan bahwa $P B L$ merupakan salah satu alternatif model pembelajaran yang memungkinkan peserta didik dapat meningkatkan kemampuan kognitif, karena di dalam $P B L$ peserta didik dihadapkan pada masalah yang harus dipecahkan melalui bimbingan guru. Menurut Akinoglu and Tandogan (2007: 71) pembelajaran bukan lagi proses yang standar dalam proses pembelajaran aktif, tetapi berubah ke dalam bentuk yang disesuaikan, dimana dikembangkan keterampilan pemecahan masalah, berpikir kreatif, dan belajar.

Menurut Sanjaya (2006: 313-214) alasan $P B L$ perlu dikembangkan meliputi 3 aspek, yakni: (1) dilihat dari aspek psikologi belajar; $P B L$ berdasarkan kepada psikologi kognitif yang berangkat dari asumsi bahwa belajar adalah proses perubahan tingkah laku berkat adanya pengalaman. Belajar bukan semata-mata proses menghafal sejumlah fakta, tetapi suatu proses interaksi secara sadar antara individu dengan lingkungannya. Melalui $P B L$ perkembangan peserta didik tidak hanya terjadi pada aspek kognitif saja tetapi juga pada aspek afektif dan psikomotor melalui penghayatan secara internal akan masalah yang dihadapi; (2) Dilihat dari aspek filosofis tentang fungsi sekolah sebagai arena atau wadah untuk mempersiapkan peserta didik agar dapat hidup di masyarakat. $P B L$ sangat penting dikembangkan dalam rangka memberikan latihan dan kemampuan setiap individu untuk dapat menyelesaikan masalah yang dihadapinya; (3) dilihat dari konteks perbaikan kualitas pendidikan, $P B L$ dapat digunakan untuk memperbaiki sistem pembelajaran, dimana selama ini kemampuan peserta didik untuk menyelesaikan suatu masalah kurang diperhatikan guru.

Metode $P B L$ dapat meningkatkan interaksi sosial dan prestasi belajar peserta didik seperti penelitian pada salah satu SMAN di Surakarta Tahun Pelajaran 2011/2012 (Dewi dkk., 2013: 19), dengan mempelajari materi penjernihan air peserta didik diharapkan mampu memecahkan masalah kekurangan air bersih yang masih banyak dirasakan oleh masyarakat (Ornelia, 2009: 1). Seperti yang diutarakan (Barell, 2007: 179) bahwa salah satu unsur dalam $P B L$ adalah masalah harus berangkat dari masalah di dunia nyata. Salah satu materi yang sangat cocok dengan PBL adalah materi dengan topik penjernihan air, karena topik ini sangat erat kaitannya dengan kehidupan sehari-hari. Bila 
dikaji lebih jauh topik penjernihan air merupakan bagian dari pokok bahasan sistem koloid.

Berdasarkan latar belakang dan beberapa pendapat di atas penulis mencoba untuk melakukan penelitian yang berjudul "Analisis Kemampuan Kognitif Peserta Didik Melalui Problem Based Learning pada Sub Materi Penjernihan Air”.

Penelitian ini bertujuan untuk mengidentifikasi peningkatan kemampuan kognitif peserta didik SMK kelas XI setelah memperoleh pembelajaran dengan model $P B L$ pada kelompok tinggi, sedang dan rendah pada sub materi penjernihan air. Tujuan lainnya untuk mengetahui persepsi tanggapan peserta didik terhadap implementasi pembelajaran $P B L$ pada sub materi penjernihan air.

\section{METODE PENELITIAN}

Subyek dari penelitian ini adalah 31 peserta didik dari salah astu SMK Negeri di Cimahi. Peserta didik dikelompokkan menjadi tiga kelompok yang berbeda, yakni kelompok peserta didik yang memiliki kemampuan tinggi (kelompok tinggi), kelompok peserta didik yang memiliki keterampilan sedang (kelompok sedang), dan kelompok peserta didik yang memiliki keterampilan rendah (kelompok rendah).

Cara pengelompok peserta didik dilakukan dengan menghitung rata-rata nilai ulangan harian mata pelajaran kimia dan standar deviasi. Rumus mencari rata-rata (mean) sebagai berikut:

$$
\text { Mean }=\frac{\sum \mathrm{x}}{\mathrm{N}}
$$

(Arikunto, 2012: 299)

Keterangan :

$$
\begin{aligned}
& \sum \mathrm{x}=\text { Jumlah skor } \\
& \mathrm{N}=\text { Jumlah peserta didik }
\end{aligned}
$$

Rumus untuk mencari standar deviasi:

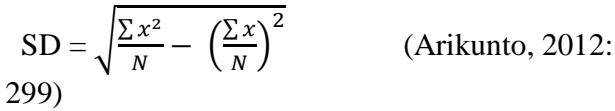

Keterangan:

$\mathrm{SD}=$ Standar deviasi

$\frac{\sum x^{2}}{N}=$ Tiap skor dikuadratkan lalu dijumlahkan kemudian dibagi dengan $\mathrm{N}$. $\left(\frac{\sum x}{N}\right)^{2}=$ Tiap skor dijumlahkan, dibagi dengan $\mathrm{N}$ lalu dikuadratkan.

Hasil perhitungan dengan menggunakan cara di atas akan menghasilkan tiga kategori kelompok peserta didik sebagai berikut:

1. Peserta didik yang memiliki nilai rata-rata ulangan harian $>($ mean $+\mathrm{SD})$, digolongkan ke dalam kategori peserta didik kelompok tinggi.

2. Peserta didik yang memiliki nilai rata-rata ulangan harian antara $($ mean $+\mathrm{SD})>($ mean - SD), digolongkan ke dalam kategori kelompok sedang.

3. Peserta didik yang memiliki nilai rata-rata ulangan harian < (mean - SD), digolongkan ke dalam kategori kelompok rendah.

Berdasarkan hasil perhitungan yang telah dilakukan, peserta didik yang termasuk ke dalam kelompok tinggi sebanyak 6 orang, peserta didik kelompok sedang sebanyak 18 orang, dan peserta didik kelompok rendah sebanyak 7 orang.

Penelitian ini menggunakan desain OneGroup Pretest-Posttest Design. 25 soal pilihan ganda digunakan untuk melihat sejauhmana kemampuan kognitif peserta didik sebelum dan sesudah pelaksanaan pembelajaran dengan metoda $P B L$ antara kelompok tinggi, kelompok sedang, dan kelompok rendah.

Tahapan Pembelajaran $\boldsymbol{P B L}$ (a) Orientasi Peserta didik terhadap Masalah, (b) Mengorganisasi kan peserta didik belajar (c) Membimbing penyelidikan individual dan kelompok, (d) Mengembangkan dan menyajikan hasil karya, dan (e) Menganalisis dan mengevaluasi proses pemecahan masalah

Peningkatan kemampuan kognitif dan berpikir kreatif peserta didik sebelum dan sesudah pembelajaran. Pengolahan data dihitung berdasarkan skor $\mathrm{N}$-gain yang dinormalisasi dengan menggunakan rumus yang dikemukakan oleh (Hake, 1998: 65), dengan rumus sebagai berikut :

$$
\begin{gathered}
N-\text { gain }=\frac{s_{\text {post }}-S_{\text {pre }}}{S_{\text {max }}-S_{\text {pre }}} \times 100 \% \\
\text { Dimana, } S_{\text {post }}=\text { Nilai postes } ; S_{\text {pre }}=\text { Nilai; } S_{\text {max }}=
\end{gathered}
$$
Nilai maksimal yang diperoleh peserta didik. 
Terdapat tiga kategori peningkatan $\mathrm{N}$-gain ditunjukkan pada Tabel 3.14.

Tabel 3.14. Klasifikasi $N$-gain Hake

\begin{tabular}{|c|c|}
\hline $\begin{array}{c}\text { Kategori Perolehan } N \text { - } \\
\text { gain }\end{array}$ & Keterangan \\
\hline$N$-gain $>0,70$ & Tinggi \\
\hline $0,3<N$-gain $>0,70$ & Sedang \\
\hline$N$-gain $<0,30$ & Rendah \\
\hline
\end{tabular}

\section{HASIL DAN PEMBAHASAN}

a. Profil Peningkatan Kemampuan Kognitif Peserta Didik SMK Kelas XI Secara Keseluruhan

Berdasarkan data dari tes awal dan tes akhir dapat dilihat bahwa implementasi pembelajaran model $P B L$ dapat meningkatkan hasil belajar dari peserta didik padatopik penjernihan air. Data dianalisis dengan menggunakan SPSS 21. Hasil dapat dilihat pada Tabel 1. Dan untuk perbandingan dapat dilihat pada Grafik 1

$22 \%$ peserta didik yang mempunyai nilai dibawah KKM, sedangkan $78 \%$ berhasilkan mempunyai nilai di atas KKM. Dan bila kita lihat perolehan rata-rata nilai untuk tiap kelompok peserta didik kategori tinggi, sedang, dan rendah peserta didik masing-masing mempunyai nilai rata-rata 81,$33 ; 77,56$; dan 76,57 . Ketiga nilai tersebut menunjukkan nilai diatas nilai Kriteria Ketuntasan Minimal (KKM) yaitu 75.

Dari data diketahui adanya peningkatan kemampuan kognitif setelah diberikan pembelajaran $P B L$ pada materi penjernihan air hal ini dikarenakan pembelajaran dengan model $P B L$ dapat membuat peserta didik lebih aktif sehingga peserta didik dapat membangun pengetahuannya sendiri melalui permasalahan, seperti yang dikemukakan oleh Arends (2012: 396) dan inti Barell (2007: 174). PBL dapat merubah standar kurikulum dari peserta didik pasif menjadi peserta didik terlibat aktif dalam memecahkan masalah dan pertanyaan.

Dengan $P B L$ cara belajar peserta didik mengalami perbaikan hal ini sesuai dengan hasil penelitian dari Tan (2009: 16) mengemukakan bahwa pada prinsipnya $P B L$ ditekankan untuk meningkatkan dan memperbaiki cara belajar dengan tujuan untuk menguatkan konsep dalam kondisi nyata, mengembangkan keterampilan berfikir tingkat tinggi, keterampilan memecah- kan masalah, meningkatkan keaktifan belajar peserta didik, mengembangkan keterampilan membuat keputusan, menggali informasi, meningkatkan percaya diri, tanggung jawab, bekerja sama, dan komunikasi.

Tabel 1.

Skor Rata-rata Tes Awal dan Tes Akhir Kemampuan Kognitif untuk Kelompok Peserta Didik Kategori Tinggi, Sedang dan Rendah

\begin{tabular}{|c|c|c|c|c|c|c|c|c|c|c|c|}
\hline \multirow{2}{*}{ No } & \multirow{2}{*}{$\begin{array}{c}\text { Kategori } \\
\text { Peserta } \\
\text { didik }\end{array}$} & \multirow{2}{*}{$\begin{array}{c}\text { Jumlah } \\
\text { peserta } \\
\text { didik }\end{array}$} & \multicolumn{5}{|c|}{ Tes Awal } & \multicolumn{3}{|c|}{ Tes Akhir } & \multirow{2}{*}{$\begin{array}{l}N- \\
\text { Gain }\end{array}$} \\
\hline & & & $\begin{array}{l}\text { Skor } \\
\text { Min }\end{array}$ & $\begin{array}{l}\text { Skor } \\
\text { mak }\end{array}$ & $\begin{array}{c}\text { Mea } \\
n\end{array}$ & $\begin{array}{l}\text { Std. } \\
\text { Dev }\end{array}$ & $\begin{array}{c}\mathrm{r} \\
\mathrm{Mi} \\
\mathbf{n}\end{array}$ & $\begin{array}{l}\text { Skor } \\
\text { mak }\end{array}$ & Mean & $\begin{array}{l}\text { Std. } \\
\text { Dev }\end{array}$ & \\
\hline 1 & $\begin{array}{l}\text { Kel. } \\
\text { Tinggi }\end{array}$ & 6 & 24 & 56 & 42.67 & 10.63 & 68 & 92 & 81.33 & 8.64 & 68 \\
\hline 2 & $\begin{array}{l}\text { Kel. } \\
\text { Sedang }\end{array}$ & 18 & 28 & 56. & 40.22 & 8.17 & 72 & 84 & 77.56 & 4.15 & 62 \\
\hline 3 & $\begin{array}{l}\text { Kel. } \\
\text { Rendah }\end{array}$ & 7 & 6 & 11 & 8.43 & 1.51 & 72 & 84 & 76.57 & 4.86 & 66 \\
\hline & Total & 31 & 24 & 56 & 39.22 & 8.61 & 68 & 92 & 78.71 & 5.88 & 65.33 \\
\hline
\end{tabular}

\section{b. Peningkatan Kemampuan Kognitif untuk Setiap Sub Topik}

Untuk melihat peningkatan hasil kemampuan kognitif peserta didik pada topik penjernihan air melalui $P B L$ setiap topik pada kelompok tinggi, sedang, dan rendah dapat dilihat pada Tabel 2. Sedangkan untuk gambaran perbandingan peningkatan antara kelompok tinggi, kelompok sedang dan kelompok rendah untuk tiap sub topik dapat terlihat pada Grafik 2.

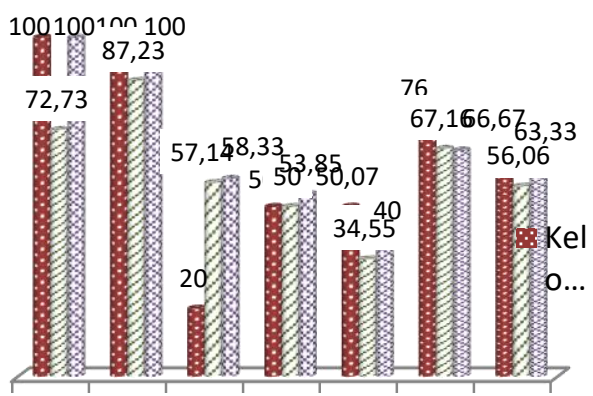

$$
\begin{aligned}
& \text { sumber Air Air sadah } \\
& \text { Media penjernihan Air } \\
& \text { percobaan penjernihan Air }
\end{aligned}
$$

Grafik 2 Perbandingan Peningkatan Kemampuan Kognitif Kelompok Tinggi, Kelompok Sedang dan Kelompok Rendah Perkosep 
Grafik 2 memperlihatkan nilai rata-rata tes awal dan tes akhir peserta didik dari kategori siswa kelompok tinggi, sedang dan rendah, serta memperlihatkan peningkatan kenaikan kemampuan kognitif untuk setiap sub topik dengan menghitung rerata persen $\mathrm{N}$ Gain dari masing-masing kategori peserta didik.

TABEL 2

Skor Rata-rata Tes Awal dan Tes Akhir Kemampuan Kognitif Tiap Sub Topik Kelompok Peserta Didik Kategori Tinggi, Sedang dan Rendah

\begin{tabular}{|l|l|r|c|c|c|c|c|c|c|c|}
\hline \multirow{2}{*}{ No. } & \multirow{2}{*}{ Sub Topik } & \multicolumn{6}{|c|}{ Kategori Peserta Didik } \\
\cline { 3 - 11 } & & \multicolumn{3}{|c|}{ Tinggi } & \multicolumn{3}{|c|}{ Sedang } & \multicolumn{3}{c|}{ Rendah } \\
\cline { 3 - 12 } & & T1 & T2 & $\begin{array}{c}\text { \%N- } \\
\text { g }\end{array}$ & T1 & T2 & $\begin{array}{c}\text { \%N- } \\
\text { g }\end{array}$ & T1 & T2 & $\begin{array}{c}\text { \%N } \\
\text {-g }\end{array}$ \\
\hline 1 & Sumber Air & 75,00 & 100 & $100^{*}$ & 69,44 & 91,67 & 72,73 & 42,86 & 100 & $100^{*}$ \\
\hline 2 & Air Bersih & 66,67 & 100 & 100 & 56,48 & 94,44 & 87,23 & 40,48 & 100 & 100 \\
\hline 3 & Air Sadah & 58,33 & 67,00 & $20^{* *}$ & 41,67 & 75,00 & 57,14 & 14,29 & 50,00 & 58,33 \\
\hline 4 & $\begin{array}{l}\text { Air Dengan Logam } \\
\text { Pengotor }\end{array}$ & 33,33 & 67,00 & 50,00 & 27,78 & 63,89 & 50,00 & 7,14 & 57,14 & 53,85 \\
\hline 5 & $\begin{array}{l}\text { Media Penjernihan } \\
\text { Air }\end{array}$ & 22,22 & 67,00 & 50,07 & 46,30 & 64,85 & 34,55 & 28,57 & 57,14 & 40,00 \\
\hline 6 & $\begin{array}{l}\text { Efek Tyndall, } \\
\text { Adsorpsi, dan } \\
\text { Koagulasi dalam } \\
\text { penjernihan air }\end{array}$ & 17,00 & 80,00 & 76,00 & 26,00 & 76,00 & 67,16 & 23,00 & 74,00 & 66,67 \\
\hline 7 & $\begin{array}{l}\text { Percobaan } \\
\text { Penjernihan Air }\end{array}$ & 16,67 & 67,00 & 60,00 & 26,67 & 67,78 & 56,06 & 14,29 & 68,57 & 63,33 \\
\hline
\end{tabular}

Keterangan :

$$
\begin{array}{ll}
\mathrm{T} 1 & =\text { Rata-rata tes awal } \\
\mathrm{T} 2 & =\text { Rata-rata tes akhir } \\
\% \mathrm{~N}-\mathrm{g} & =\text { persen } N \text {-Gain } \\
* & =\text { persen } N \text {-Gain } \text { terbesar } \\
* * & =\text { persen } N \text {-Gain } \text { terkecil }
\end{array}
$$

Kel 1:

Analisis data untuk masing-masing sub topik dapat dilihat pada Tabel 2, pada tabel tersebut menyajikan peningkatan tertinggi terjadi pada konsep sumber air untuk peserta didik dengan kemampuan rendah dan tinggi dengan harga $\% \mathrm{~N}$-Gain sebesar $100 \%$ : dengan kriteria tinggi, sedangan konsep yang menunjukkan harga \%N-Gain terlihat pada konsep air sadah dengan nilai $\mathrm{N}$-Gain sebesar $20 \%$ denga kategori rendah dan terjadi pada kelompok peserta didik dengan kemampuan tinggi

Pada peserta didik dengan kemampuan tinggi dari tujuh sub topik mdkehjßrkkan 3 konsep yaitu pada sub topik sumber air, air bersih, dan efek Tyndall, adsorpsi, dan koagulasi dalam penjernihan air berada pada kategori tinggi, sedangkan percobaan penjer-nihan air, sub topik air dengan logam pengotor dan media penjernihan air berada pada kategori sedang.

Pada peserta didik dengan kemampuan sedang pada sub topik air bersih dan sumber air menunjukkan kategori tinggi dengan \% $\mathrm{N}$-Gain $71,73 \%$ dan $87,23 \%$. Sedangkan \% $N$-Gain terendah pada konsep air sadah sebesar $72,73 \%$ dengan kategori tinggi serta $\% \mathrm{~N}$-Gain terendah sebesar $34,55 \%$.

Dari data keseluruhan menunjukkan adanya peningkatan kemampuan kognitif setelah $P B L$, meskipun ada peningkatan dengan kategori rendah yaitu pada nilai \%N-Gain $20 \%$ untuk kelompok peserta didik dengan kemampuan tinggi pada konsep air sadah, hal ini dapat disebabkan sub topik air sadah kurang tergali maksimal hal ini dapat terlihat dari jawaban LKS pada saat mengorganisasikan peserta didik belajar jawaban-jawaban peserta didik tidak maksimal untuk pertanyaan "Carilah permasalahan-permasalahan terkait dengan air yang ada dalam artikel yang ada dalam artikel yang berhubungan dengan masalah yang diakibatkan oleh air bagi kehidupan?"

Diperoleh jawaban dari masing-masing kelompok sebagai berikut:

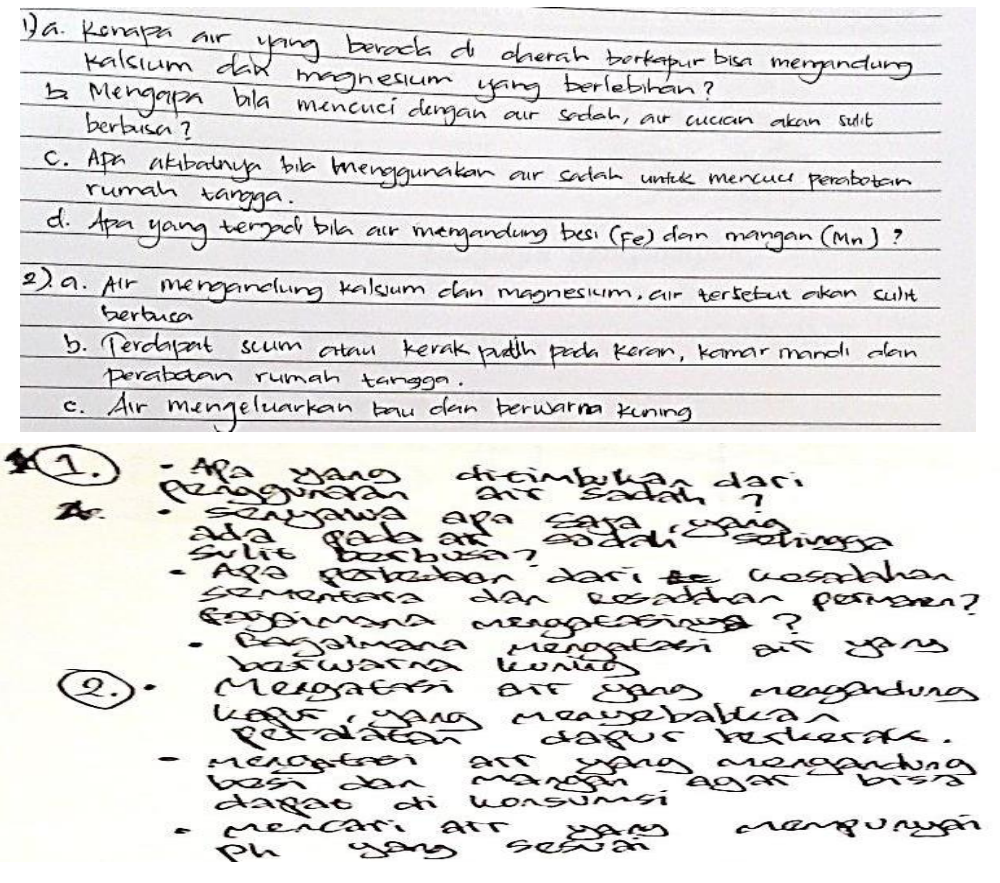




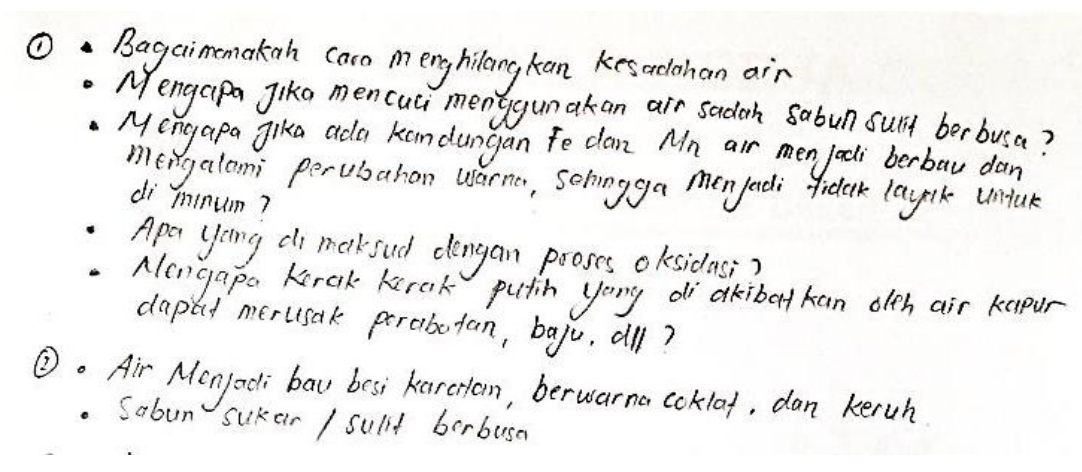

1). a. APd penyebab Alir di rumah kita menadi air ug Mencjanclung) kapur (sadah?

c. Ausdk karend air sadah? mengandusta) besi ( $\mathrm{fel}$ dan mangan (Mn)?

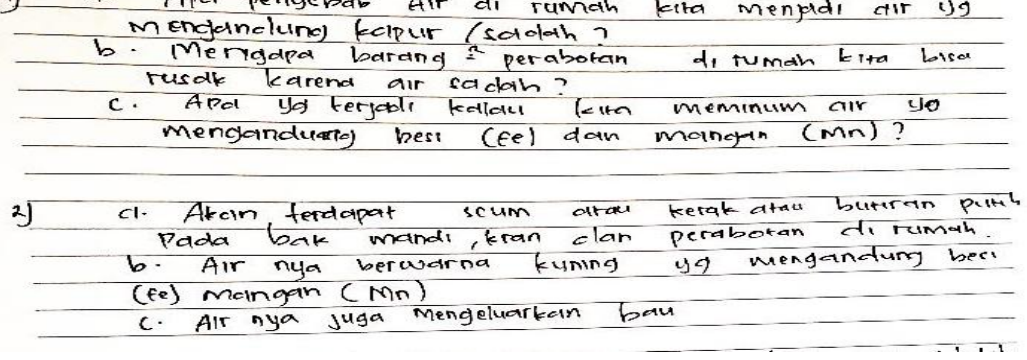

- Bagaimana cara minghalangrean kesuclatan air?

- Mengapa jika mencuci minggunakan ar sadah sabun sulit berbusa?

- Mengapa reka ada Kanduningan fe dan Mn air monjadi berbao

dan mengalami perubuhan warna. sehingga tidak logak untok di ronsumsi?

- Apa yang dimaksud dengan proses oksidasi?

- Mengapa kerak - Merak putih yang di akebatran oleh air kapor dapat merusak perabotan. pukatan dil?.

Dari jawaban-jawaban peserta didik tergambarkan bahwa peserta didik menjawab sangat sederhana peserta didik tidak menjelaskan lebih lanjut mengenai air sadah lebih mendalam, tetapi peserta didik sudah dapat mengajukan berbagai macam pertanyaan.

Hal ini terkait dengan pernyataan mengenai sulitnya mengimplementasikan $P B L$ yang dikemukakan oleh Akinoglu \& Tandagon (2007: 73) guru kesulitan mengubah pola mengajarnya, meskipun dari hasil observasi yang dilakukan terhadap guru semua tahap $P B L$ terlaksana dalam kegiatan pembelajaran. Hal ini sesuai dengan hasil wawancara pada guru yang membantu mengimplementasikan $P B L$ tercermin pada pertanyaan dan jawaban no. 7 seperti berikut transkrip wawancara tersebut:
Peneliti 7: "Adakah kendala yang Bapak rasakan sewaktu mengimplementasikan pembelajaran dengan model $P B C$ "

Guru 7: "Ada, pertama sulit spengetahuannwa sekali mengkondisikan anak untuk membangun pengetahuannwa sendin mungkin karena belum terbiasas kedua kondisi ini juga diperburuk dengan siswanya yang. kurang baik dalam hal motivasi maupun kemampuan akademiknva, diperlukan waktu yang relative lama dalam implementasi model PBL ini, tetapi hal ini mungkin terkjadi karena sava sendiri merasakan sulitnua merubah pola mengajar saya dari metode konvensional ke metode PBL."

\section{SIMPULAN DAN SARAN}

\section{Simpulan}

Tahap-tahap pembelajaran yang diterapkan meliputi menyajikan masalah terkait dengan penjernihan air melalui artikel yang berjudul "Permasalahan Air Tanah", mengidentifikasi masalah yang akan diselidiki, menggiring peserta didik untuk melakukan penyelidikan, menggabungkan informasi yang diperoleh secara bersama-sama dan mengemukakan apa yang diperoleh. Model $P B L$ dapat meningkatkan kemampuan kognitif peserta didik. Peningkatan kemampuan kognitif peserta didik kelompok tinggi, kelompok sedang dan kelompok rendah, ketiganya menunjukkan adanya peningkatan pada kategori sedang.

Secara umum dapat disimpulkan bahwa melalui pembelajaran $P B L$ yang terdiri atas lima tahapan yaitu mengorientasi peserta didik pada masalah, mengorientasi peserta didik untuk belajar, membimbing penyelidikan individual maupun kelompok, mengembangkan dan menyajikan hasil karya, menganalisis dan mengevaluasi dapat meningkatkan kemampuan kognitif peserta didik.

\section{Saran}

Model pembelajaran $P B L$ yang telah dilaksanakan salah satu SMK Negeri di Cimahi, diharapkan dapat dilaksanakan secara berkelanjutan agar kemampuan kognitif siswa dalam pembelajaran kimia semakin berkembang. Guru harus mengupayakan suatu pembelajaran agar kemampuan kognitif seorang siswa mampu mempengaruhi tumbuh kembangnya kemampuan kognitif. 


\section{DAFTAR PUSTAKA}

Akinoglu, O. and Tandogan, R.O. 2007. "The Effects of Problem-Based Active Learning in Science Education on Students' Academic Achievement, Attitude and Concept Learning". Eurasia Journal of Mathematics, Science \& Technology Education. 3, (1), 71-81.

Arends, R. (2012). Learning to Teach (ninth ed.). Americas, New York: McGraw-Hill

Arikunto. (2006). Dasar-dasar Evaluasi Pendidikan. Jakarta: Bumi aksara

Arnyana, I.B. P. 2006. "Pengaruh Penerapan Strategi Pembelajaran Inovatif pada Pembelajaran Biologi terhadap Kemampuan Berpikir Kreatif Peserta didik SMA". Jurnal Pendidikan dan Pengajaran IKIP Negeri Singaraja. 3, 496-518

Barell, J. (2007). Problem-based learning-An inquiry approach (2nd ed.). Thousand Oaks, CA: Corwin Press.

Dewi, R. S., dkk. (2013). "Upaya peningkatan Interaksi Sosial dan Prestasi Belajar Siswa dengan koloid di SMAN 5 Surakarta Tahun Pelajaran 2011/2012”. Jurnal Pendidikan Kimia. 2, (1), 5-20
Hake. 1998. "Interactive-engagement versus traditional methods: A six-thousand-student survey of mechanics test data for introductory physics courses". Am. J. Phys. 66, (1), $64-74$

Muntaha dan Hartono. (2013). "Pengembangan Perangkat Pembelajaran Moedl Problem Based-Learning untuk Meningkatkan Kemampuan Berpikir Kreatif'. Journal of Primary Educational. 2, (2), 116-119

Ornellia, H. (2009). Penerapan Self Assessment dalam Menilai Laporan Siswa SMA pada Praktikum Penjernihan Air. Skripsi Jurusan Pendidikan Kimia. Universitas Pendidikan Indonesia, Bandung

Sanjaya, W. (2006). Strategi Pembelajaran Berorientasi Standar Proses Pendidikan: Jakarta: Kencana Prenada Media.

Tan, O. S. 2009. Problem-based Learning and Creativity. Singapore Cengage Learning Asia Pte Ltd.

Wulandari, W. (2011). Problem Based Learning untuk Meningkatkan Keterampilan Berpikir Kreatif dan Penguasaan Konsep Siswa pada Materi Larutan Penyangga. Tesis pada SPs UPI: Tidak diterbitkan 